Присадочную проволоку подают отдельным подающим механизмом, обеспечивающим стабильную скорость подводимой проволоки, а также имеющим возможность плавной ее регулировки. Присадочная проволока изолированная от тока не приводит к возникновению дугового разряда между ней и наплавочной ванной. Использование присадочных проволок из интерметаллидных материалов, позволяет получать заданные физико-механические свойства наплавленного металла (например, твердость, износостойкость, работоспособность и др.). За счет отбора тепла присадочной проволокой из сварочной ванны снижается склонность наплавленного слоя к образованию микротрещин. Повышение твердости и износостойкости швов достигается формированием инварных покрытий.

Также возможно применение многослойной наплавки с разной структурой и свойствами наплавленных слоев.

Способ осуществляется следующим образом.

Деталь цилиндрической формы закрепляют в приспособлении, установленном на вращателе, например шпинделе токарно-винторезного станка (не показан), который обеспечивает заданную скорость вращения детали Vдет. К поверхности детали через ролики подводят плавящийся электрод со скоростью Vосн. На плавящийся электрод и деталь через токоподвод подают напряжение, при этом между электродом и деталью зажигается дуга. На поверхности детали образуется ванна расплавленного металла. В наплавочную ванну через ролики перед и после плавящегося электрода по направлению вращения детали на расстоянии у и $\mathrm{x}$ соответственно подают две присадочные проволоки со скоростью Vпр, полностью изолированные от тока. Наплавку ведут под слоем флюса, который подают из бункера при помощи лотка . Переднюю присадочную проволоку подают под углом $\alpha$ относительно плавящегося электрода, а заднюю присадочную проволоку - под углом 1.

$$
* * *
$$

1. Виноградов А.Н. [и др.] Способ и устройство для восстановления наплавкой поверхностей тел вращения // Вестник Саратовского государственного технического университета. - 2010. - № 45. C. 49-54.

2. Ковтунов, А.И. Технология формирования износостойких покрытий / А.И. Ковтунов, Т.В. Чермашенцева, Д.А. Семистенов // Упрочняющие технологии и покрытия. - 2009. - №7. - С. 12-14.

3. А.И. Захаров, Физики из прецизионных сплавов с конкретными тепловые свойства (Металлургия, Москва, 1986 г.), Всероссийский. 239 с.

\title{
Муравьёв К.А. \\ Исследование химической неоднородности в наплавленном металле при сварке конструкционных сталей
}

Филиал Тюменского индустриального университета в г. Сургуте Сургутский институт нефти и газа (Россия, Сургут)

doi:10.18411/spc-12-02-2018-20

idsp: 000001:spc-12-02-2018-20

Основные положения. Для выявления причин и условий образования горячих и холодных трещин в сварных швах и зоне термического влияния необходим анализ формирования химической неоднородности наплавленного металла, в частности, вызванной влиянием наиболее опасного элемента — серы.

В настоящее время разработанные расчетные методы оценки степени развития химической неоднородности при ручной электродуговой сварке покрытыми электродами пригодны только для случаев контактирования двух чистых металлов или сплавов одного состава. Поэтому в последние годы делаются попытки полуколичественной оценки химической неоднородности сварного шва. 
Известно [8], что подвижность большинства элементов замещения при переходе из жидкого состояния в твердое, резко падает (коэффициент диффузии на 3-5 порядков ниже), и длительность пребывания при повышенных температурах в реальном сварочном процессе недостаточна для реализации процессов развития химической неоднородности материала шва. В этом случае главную роль играет гетерогенная диффузия примесей элементов внедрения.

Характер распределения примеси при гетерогенной диффузии в зоне контакта твердой и жидкой фаз зависит от коэффициента распределения К, представляющего растворимость элементов в твердой и жидкой фазах, коэффициентов диффузии в этих фазах Dт и Dж, продолжительности процесса $t$ и градиента концентрации примеси на границах сплавления. В этом случае задачу диффузии примеси в двух средах при частных граничных (предельных) условиях можно сформулировать следующими выражениями:

$$
\begin{aligned}
& \text { 1. } \frac{d C_{T}}{d t}=D_{T} \frac{d^{2} C}{d x^{2}}, \mathrm{x}<0 ; \\
& \frac{d C_{T}}{d t}=D_{T} \frac{d^{2} C}{d x^{2}}, \mathrm{x}>0 ; \\
& \text { 2. } \quad C_{T}=C_{T 0} \text { при } \mathrm{t}=0 \text { и } \mathrm{x}<0 ;
\end{aligned}
$$

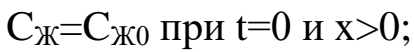

$$
\text { 3. } D_{T}\left(\frac{d C_{T}}{d x}\right)_{x=0}=D_{Ж}\left(\frac{d C_{Ж}}{\mathrm{dx}}\right)_{\mathrm{x}=0},
$$

на границах раздела при всех значениях $t$;

$$
\text { 4. } \int_{-\infty}^{0}\left(C_{T 0}-C_{T}\right) d x=\int_{-\infty}^{0}\left(C_{\text {ж0 }}-C_{\text {Ж }}\right) d x ;
$$

5. $\frac{C_{T}}{C_{\text {Ж }}}=K$ в равновесном состоянии.

В таком случае решения имеют следующий вид [9]:

$$
\begin{aligned}
& C_{T}(x, t)=C_{T 0}-\frac{C_{T 0}-K C_{\text {ж0 }}}{K \sqrt{D_{T} / D_{\text {ж }}}+1}\left[1+e r f\left(\frac{x}{2 \sqrt{D_{T}} t}\right)\right] \text { при } \mathrm{x}<0 \text {; } \\
& C_{\text {Ж }}(x, t)=C_{\text {Ж0 }}-\frac{C_{T 0}-K C_{\text {ж0 }}}{K+\sqrt{D_{Ж} / D_{\mathrm{IT}}}}\left[1-\operatorname{erf}\left(\frac{x}{2 \sqrt{D_{ж}} t}\right)\right] \text { при х }>0 ;
\end{aligned}
$$

где $\mathrm{C}_{\mathrm{T}}(\mathrm{x}, \mathrm{t})$ и $\mathrm{C}_{ж}(\mathrm{x}, \mathrm{t})$ - концентрация элементов примеси соответственно в твердой и жидкой фазах при $t>0$ на различных расстояниях от границы, $\mathrm{C}_{\mathrm{T0}}$ и $\mathrm{C}_{\text {жо }}$ - начальные концентрации примеси в твердой и жидкой фазах $(t=0)$. Так, при наплавке или сварке однородного материала $\mathrm{C}_{0}=\mathrm{C}_{\mathrm{T} 0}=\mathrm{C}_{\text {ж0 }}$

Анализ уравнений (1) и (2) показывает, что если $K=1$, то возрастает роль, градиента концентрации на границе сплавления $\Delta \mathrm{C}_{0}=\mathrm{C}_{\mathrm{T} 0}-\mathrm{C}_{ж 0}$ :

$$
\begin{aligned}
& C_{T}(x, t)=C_{T 0}-\frac{\Delta C_{0}}{\sqrt{D_{T} / D_{\text {Ж }}}+1}\left[1+\operatorname{erf}\left(\frac{x}{2 \sqrt{D_{T}} t}\right)\right] \text { при х }<0 ; \\
& C_{\text {ж }}(x, t)=C_{\text {Ж0 }}-\frac{\Delta C_{T 0}}{1+\sqrt{D_{\text {K }} / D_{\mathrm{IT}}}}\left[1-\operatorname{erf}\left(\frac{x}{2 \sqrt{D_{\text {T }}} t}\right)\right] \text { при х }>0 ;
\end{aligned}
$$

Если $D_{T}=D_{\text {ж }}$ (отсутствие границы фаз, а температура в металле постоянная), тогда 


$$
\begin{gathered}
C(x, t)=C_{I 0}-\frac{\Delta C_{0}}{2}\left[1+\operatorname{erf}\left(\frac{x}{2 \sqrt{D} t}\right)\right] \text { при } \mathrm{x}<0 ; \\
C_{0}(x, t)=C_{I I 0}-\frac{\Delta C_{T 0}}{2}\left[1-\operatorname{erf}\left(\frac{x}{2 \sqrt{D} t}\right)\right] \text { при } \mathrm{x}>0 ;
\end{gathered}
$$

Следует отменить, что величина параметра $D_{T}$ зависит от температуры, концентрации других элементов, структуры, природы примеси, напряженного состояния.

Экспериментами установлено [2], что

$$
\begin{aligned}
& \mathrm{D}_{\mathrm{T}}=1 \cdot\left(10^{-7}-10^{-6}\right) \mathrm{cm}^{2} / \mathrm{c} \\
& \mathrm{D}_{Ж}=1 \cdot\left(10^{-4}-10^{-6}\right) \mathrm{cm}^{2} / \mathrm{c} .
\end{aligned}
$$

Продолжительность контактирования двух фаз «твердый - жидкий металл» вполне определима. Коэффициент распределения $\left(\mathrm{K}_{0}=\mathrm{C}_{\mathrm{T}} / \mathrm{C}_{ж}\right)$ в зависимости от легирующих элементов изменяется. При наличии интенсивного перемешивания величина $K \approx 1$.

Для большинства практических случаев неизвестны значения эффективного распределения $K, D_{T}, D_{ж}$ и длительность контактирования фаз. Поэтому исследователями при расчёте химической неоднородности для большинства случаев диффузии элементов замещения, величина $K$ не учитывается.

В этом случае используют следующие выражения:

$$
\begin{gathered}
C_{T}=C_{T 0}-\frac{\Delta C_{0}}{\sqrt{D_{T} / D_{\text {ж }}}+1} \cdot \mathrm{B} ; \\
C_{\text {Ж }}=C_{\text {Ж0 }}-\frac{\Delta C_{0}}{\sqrt{D_{\text {Ж }} / D_{\mathrm{T}}}} \cdot \mathrm{B} ; \\
\text { где } \Delta \mathrm{C}_{0}=\mathrm{C}_{\mathrm{T} 0}-\mathrm{C}_{\text {Ж0}} ; \\
\mathrm{B}=1-\operatorname{erf}\left(\frac{\mathrm{x}}{2 \sqrt{\mathrm{D} t}}\right)=1-\Phi(\mathrm{U}) ;
\end{gathered}
$$

где $\Phi(U)$ - интеграл вероятности.

Из анализа приведенных выше уравнений следует, что если $K<1$, то диффузия происходит из основного металла (твердого) в металл шва. Подавить диффузионные процессы можно в случае, когда длительность контактирования жидкой и твердой фаз приближается к времени оседлой жизни атома на границе раздела фаз (для атомов углерода около $1 \cdot 10^{11} \mathrm{c}$ ).

При $K>1$ происходит диффузия из жидкого металла в твердый, в основном по границам зерен.

Таким образом, уравнения (1-4) для гетерогенной диффузии примесей неприменимы в случае контакта двух чистых разнородных металлов. Эти уравнения не учитывают наличия двухфазной области и изменения коэффициента $D$ в зависимости от концентрации элементов. В то же время, эти уравнения позволяют определять влияние перераспределения легирующих элементов и образования новых фаз на возникновение кристаллизационных и подсолидусных трещин.

Методика исследования химической ликвации серы в металле шва. Анализ дендритной ликвации серы производили с помощью сканирующего электронного микроскопа марки JSM-35CF фирмы «Джеол» (Япония), оснащенного приставкой для микрорентгеноспектрального анализа. Исследуемые швы 
предварительно подвергали травлению на первичную структуру по методике, изложенной в работе [7].

На первом этапе по полученному на экране микроскопа изображению первичной структуры выбирали участки для анализа.

На рис. 1 и 2 соответственно показано схематически положение на шлифе анализируемого участка и его увеличенное изображение, получаемое на экране микроскопа.

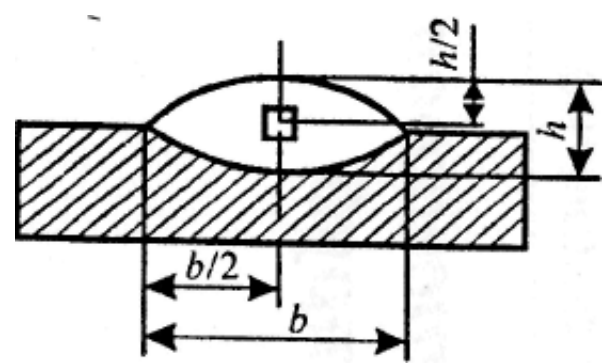

Рис. 1. Положение на шлифе анализируемого участка

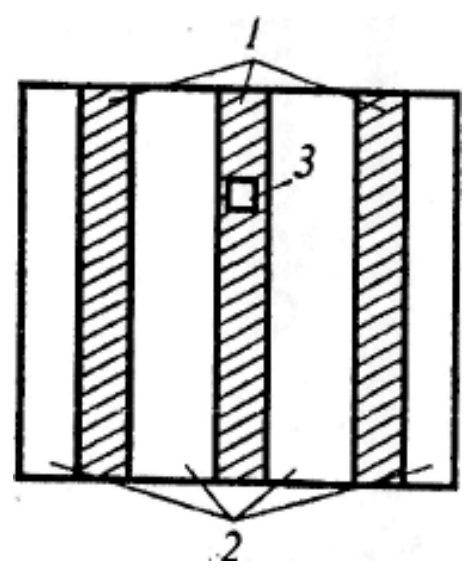

Pис. 2. Схематичное изображение участка, получаемого на экране микроскопа: 1 междендритные гранииы, 2 - дендриты, 3 - участок сканирования

Результаты, полученные при оценке погрешности анализа микрораспределения серы, свидетельствуют о том, что она не превышает 5\%.

Дендритную ликвацию элементов определяли, проведя 30-40 измерений интенсивности их характеристического рентгеновского излучения от дендритов и междендритных границ. При этом область сканирования микрозонда ограничивалась поперечными размерами границ и оставалась практически неизменной - 4х8 мкм. Время счета импульсов характеристического рентгеновского излучения на каждом участке сканирования составляло $40 \mathrm{c}$. На завершающем этапе измеряли фоновую интенсивность характеристического рентгеновского излучения элемента. Условия этих измерений отличались от предыдущих только тем, что перед их осуществлением смещали кристалл-анализатор от положения, соответствующего максимуму интенсивности характеристической линии. Полученные результаты обрабатывали с помощью следующих соотношений: $I_{\text {Т.Д }}^{3}=I_{\text {Т.Д.СР }}^{3}-I_{\text {Ф.СР }}^{3}$,

где $I_{\text {т.Д }}^{3}$ - интенсивность характеристического рентгеновского излучения элемента, соответствующая его средней концентрации в теле дендритов; $I_{\text {т.д.ср }}^{3}$ зарегистрированное среднее значение интенсивности характеристического 
рентгеновского излучения элемента от дендритов; $I_{\text {Ф.СР }}^{3}-$ зарегистрированное среднее значение интенсивности фононого рентгеновского излучения элемента;

$$
\begin{aligned}
& I_{\text {Г.Д }}^{3}=I_{\text {Г.Д.СР }}^{3}-I_{\text {Ф.СР }}^{3}, \\
& \text { где } I_{\text {Г.Д }}^{3}-\text { интенсивность характеристического рентгеновского излучения }
\end{aligned}
$$
элемента, соответствующая его средней концентрации на междендритных границах;

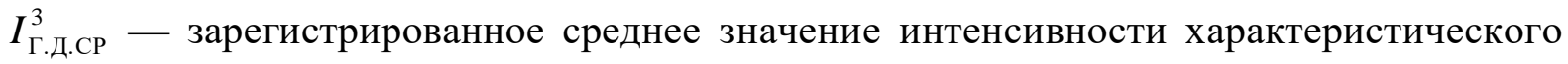
рентгеновского излучения элемента от междендритных границ;

$$
\mathrm{K}_{Л}^{3}=I_{\Gamma . Д}^{3} / I_{\Phi . С Р}^{3},
$$

где $\mathrm{K}_{\text {Л }}^{3}$ - коэффициент ликвации элемента.

Необходимо отметить, что при определении коэффициентов ликвации серы не учитывались значения интенсивностей, зарегистрированные при совмещении участков сканирования микрозонда с неметаллическими включениями. Поэтому соблюдение постоянного положения анализируемого участка на исследуемых шлифах позволило при прочих равных условиях проследить влияние химического состава металла шва на уровень дендритной ликвации серы и исключить влияние других факторов.

Методика планирования экспериментов. Для исследования влияния химического элементного состава сварного шва на дендритную ликвацию серы (коэффициент ликвации Кs) использовали симплекс-решетчатое планирование эксперимента. Его достоинство состоит в необходимости минимального количества опытов и возможности последовательно уточнять аппроксимацию эксперимента математической моделью. Поэтому в данном случае факторное пространство представляет собой симплекс-правильный треугольник для трех факторов, в частности, состава металла. Эксперимент ставится на основе стандартных матрицпланов. При любом количестве компонентов составляется минимальный план линейный, после реализации которого проверяют адекватность модели. Если она не адекватна, то наращивают количество опытов для модели следующего порядка квадратной и т. д. Общий вид полиномиальных моделей следующий.

Линейная -

$$
y=\sum_{1}^{k} b_{i} x_{i}
$$

где $\mathrm{b}_{\mathrm{i}}=\mathrm{y}_{\mathrm{i}}-$ коэффициент регрессии.

Квадратная -

$$
y=\sum_{1}^{k} b_{i} x_{i}+\sum_{1 \leq i \leq j \leq k}^{k} b_{i j} x_{i} x_{j}
$$

где $b_{i j}=4 y_{i j}-2 y_{i}-2 y_{j}$.

Специальная кубическая -

$$
y=\sum_{1}^{k} b_{i} x_{i}+\sum_{1}^{k} b_{i j} x_{i} x_{j}+\sum b_{i j k} x_{i} x_{j} x_{k}
$$

где $b_{i j k}=27 y_{i j k}-12\left(y_{i j}+y_{i k}+y_{j k}\right)+3\left(y_{i}+y_{j}+y_{k}\right)$.

Кубическая -

$$
y=\sum b_{i} x_{i}+\sum b_{i j} x_{i} x_{j}+\sum b_{i j k} x_{i} x_{j} x_{k}+\sum y_{i j} x_{i} x_{j}\left(x_{i}-x_{j}\right),
$$

где $\beta_{i j}=\frac{9}{4}\left(y_{i j k}+y_{i j j}-y_{i}-y_{j}\right)$, 


$$
\begin{aligned}
b_{i j k}=27 y_{i j k} & -\frac{27}{4}\left(y_{i i j}+y_{i j j}+y_{i k k}+y_{j j k}+y_{i i k}+y_{i k k}\right)+\frac{9}{2}\left(y_{i}+y_{j}+y_{k}\right), \\
y_{i j}= & \frac{9}{4}\left(3 y_{i i j}+3 y_{i j j}-y_{i}-y_{j}\right) .
\end{aligned}
$$

После подсчета математической модели проверяется адекватность полученных результатов по выбранным точкам при помощи критерия Стьюдента

$$
t=\frac{\Delta y \sqrt{m}}{\mathrm{~S}_{\text {ОП }} \sqrt{1+\xi}},
$$

где $\Delta y=\left|y^{\prime}-\bar{y}\right|, y^{\prime}-\bar{y}-$ соответственно расчетное и среднее наблюдаемое значения отклика по $m$ повторениям в рассматриваемой точке, $\mathrm{S}_{\mathrm{O}}-$ ошибка опыта, вычисляемая по формуле

$$
\begin{aligned}
& S_{\text {ОП }}=\sqrt{\frac{\sum_{1}^{n_{i}} \sum_{1}^{m_{i}}\left(y^{\prime}-\bar{y}\right)^{2}\left(m_{i}-1\right)}{n_{i} \sum_{1}^{m}\left(m_{i}-1\right)}} \\
& \left(\mathrm{n}_{\mathrm{i}}-\text { количество опытов с повторениями, } \xi\right. \text { - составляющая дисперсии }
\end{aligned}
$$
предсказанного значения).

Рассчитанную таким образом величину критерия Стьюдента для выбранной точки сравниваем с критическим значением ткр при степени свободы $f$ (равна количеству опытов в матрице) и уровне значимости $\alpha=0,05$. Доверительный интервал для $y$ определяем по формуле

$$
|\Delta y| \leq \frac{S_{\mathrm{O \Pi}}}{\sqrt{\mathrm{m}}} \sqrt{\xi} \cdot t_{\alpha} / 2 m_{1},
$$

где $\mathrm{m}_{1}$ - число проверочных точек.

При использовании рассматриваемого метода для изучения системы «состав свойство» допускается исследовать не всю область свойств в диапазоне изменения состава каждого компонента от 0 до $100 \%$. В данном случае выбирается область, в которой на вершинах симплекса находятся не чистые компоненты, а их смеси (квазикомпоненты). Для новой системы применяем те же стандартные планы, что и для обычной, состав же точек в новом плане пересчитываем в соответствии с долей каждого комплексного компонента $A, B$ и $C$.

При выборе интересующей нас части симплекса мы исходим из следующих предпосылок. Интервалы между минимальным максимальным содержанием каждого компонента должны быть одинаковы, активно задается процентный состав только ( $k$ 1)-го компонента, а последующий получается из суммы всех компонентов, равной $100 \%$. В этом случае состав квазикомпонентов н вершинах симплекса рассчитывается из суммы одного максимального и остальных минимальных значений компонентов:

$$
\begin{aligned}
& \mathrm{A}=\max _{1}+\min \mathrm{X}_{2}+\ldots+\min \mathrm{X}_{\mathrm{k}}, \\
& \mathrm{B}=\min _{1} \mathrm{X}_{1}+\max _{2}+\ldots+\min \mathrm{X}_{\mathrm{k}}, \\
& \mathrm{C}=\min \mathrm{X}_{1}+\max \mathrm{X}_{2}+\ldots+\max _{\mathrm{k}},
\end{aligned}
$$

где $\max X_{i}, \min X_{i}$ - максимальное и минимальное содержание компонентов в интересующих нас интервалах (пределах). 
Минимальное и максимальное содержание последнего компонента определяется из уравнений

$$
\min X_{k}=100-\max X_{1}-\sum_{2}^{k-1} \min X_{i}
$$

$\max X_{k}=100-\sum_{1}^{k-1} \min X_{i}$.

Общий состав смеси компонентов рассчитывается согласно стандартной матрице для любого числа ингредиентов.

Результаты исследований удобнее интерпретировать в такой последовательности: модели),

б) проанализировать коэффициенты регрессии полинома (математической

б) дать графический анализ экспериментальных данных,

в) произвести канонический анализ уравнений,

г) сделать численный анализ уравнений.

При анализе полученных результатов необходимо учитывать следующее.

Величина коэффициентов регрессии при факторах соответствует вкладу каждого из последних в параметр оптимизации. Это позволяет произвести ранжировку степени влияния факторов на исследуемый процесс.

Знак плюс или минус при факторе обозначает, что с его движением параметр оптимизации соответственно увеличивается или уменьшается. Знаки при квадратичных членах полинома свидетельствуют о выпуклости или вогнутости кривой, а величина коэффициента регрессии - о радиусе величины.

Интерпретация знаков эффектов взаимодействия сложнее. Если эффект имеет знак плюс, то увеличению параметра оптимизации соответствуют значения обоих факторов на нижних или на верхних уровнях. Знаку минус отвечает произведение факторов на различных уровнях. Оценив фактор взаимодействия, можно получить сведения о механизме процесса, т.к. наличие эффекта свидетельствует об определенном взаимном влиянии факторов и их комбинированном воздействии на параметр оптимизации.

Графический анализ позволяет наглядно установить степень влияния каждого фактора на параметр оптимизации, интервал его применимости, а также наметить конкретные точки на кривых.

Цель канонического (упрощенного) анализа уравнения регрессии - нахождение координат оптимума и изучение поверхности отклика в его окрестностях.

Экстремумы функций можно определять с помощью известных численных методов.

Выбор и подготовка объекта исследования. Исследования дендритной ликвации серы выполняли применительно к сварным швам на низкоуглеродистых (сталь 10 и 20) и низколегированных (09Г2С и 17Г1С) сталях, широко используемых для изготовления трубного проката нефтегазового назначения. Различные концентрации элементов в сварных швах достигались за счет изменения состава основного и электродного металла.

Швы заданного химического состава получали комбинированием соответствующих пластин и электродов. Использовались пластины толщиной 10-14 мм и электроды диаметром 4 мм с коэффициентом массы покрытия $K_{\text {м.п }}=45 \%$. Для изготовления опытных электродов в качестве базового использовали покрытие электродов марки АНО-26 /4/, в шихте которых варьировали содержание ферромарганца (марка ФМн1.0А), ферросилиция (марка ФС-15гс) и графита в интервале 0 - $10 \%$ каждого. В качестве связующего использовали натриевое жидкое стекло в количестве 25\% (сверх 100\% к массе шихты) во всех вариантах электродов. В соответствии с требованиями плана эксперимента было изготовлено по 11 вариантов каждой системы. Содержание каждого компонента изменялось в пределах от 0 до 10\%, 
при этом суммарное содержание трех компонентов оставалось неизменным и составляло $10 \%$ (на графиках принято в условных долях за единицу). Наплавку осуществляли постоянным током обратной полярности от выпрямителя модели ВДУ 504. Режимы наплавки оставались неизменными и составляли: $I_{\mathrm{cB}}=180 \mathrm{~A}, U_{\text {д }}=22-23 \mathrm{~B}$, $v_{\mathrm{cB}}=4,5 \mathrm{MM} / \mathrm{c}$

Выбор такого режима сварки опытными электродами с основным видом покрытия обусловлен тем, что для изменения в широких пределах состава шва необходимо существенно корректировать состав покрытия, что могло повлечь за собой изменение напряжения дуги, условий кристаллизации сварочной ванны и нарушение формирования металла шва. Так, при повышенной концентрации кремния в металле шва возможно образование пор и свищей. Использование в опытных покрытиях в качестве компенсирующей добавки железного порошка обеспечило стабильность условий эксперимента.

Из полученных швов вырезали шлифы, образец для спектрального анализа и отбирали пробы металла для химического анализа.

Результаты исследований и их обсуждение. По результатам экспериментов были построены уравнения множественной регрессии пятого порядка (коэффициенты регрессии значимы на уровне $\alpha<0,05)$, которые использовались для построения линий равного уровня на тройной диаграмме. Адекватность полученных уравнений регрессии проверялась с помощью F - критерия Фишера на 5\% уровне значимости. Значение коэффициентов корреляции $r=0,97-0,99$, что свидетельствует о хорошем соответствии экспериментальных данных заданным уравнениям регрессии и возможности использования последних в качестве формальных расчетных значений.

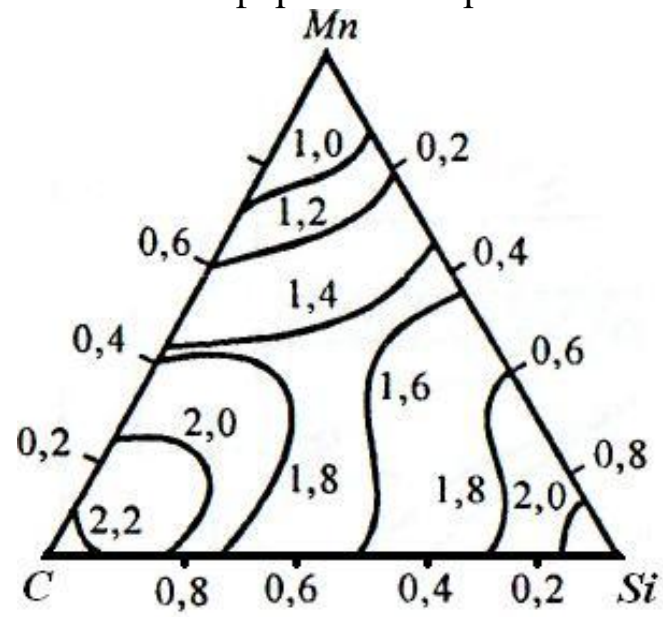

Рис. 3. Взаимное влияние $\mathrm{Si}$, Mn и С на ликвачию серы (KS) в наплавленном металле (в мол. долях)

На рис. 3 представлена тройная диаграмма системы $\mathrm{Mn}-\mathrm{Si}-\mathrm{C}$, на которой нанесены линии изоликвации серы.

Согласно приведенным данным, при доперитектических концентрациях углерода в металле шва (менее $0,1 \%$ ) дендритная ликвация серы незначительна. Это связано с кристаллизацией стали в форме $\delta$-железа, предельная растворимость серы в котором достаточно высока $(0,18 \%)$. Повышение концентрации углерода в кристаллизующемся металле (до $0,1 \%$ ) сопровождается расширением температурного интервала кристаллизации и увеличением протяженности выступов на фронте кристаллизации. Указанные изменения способствуют более полному протеканию разделительной диффузии на границе раздела фаз и выравнивающей диффузии в расплаве между первичными кристаллитами (дендритами). Кроме того, углерод, увеличивая активность серы, снижает ее растворимость в твердом растворе. В совокупности перечисленные 
факторы способствуют накоплению серы по границам первичных кристаллов, что и проявляется в повышении уровня ее ликвации.

В перитектическом диапазоне увеличение концентрации углерода в металле шва приводит к резкому повышению уровня ликвации серы. Особенно отчетливо это проявляется, начиная с концентрации углерода 0,15-0,16\%. В этом случае, кроме уже перечисленных факторов, повышению уровня дендритной ликвации серы способствует перитектическое превращение, приводящее к образованию $\gamma$ - железа. Как известно, предельная растворимость серы в $\gamma$ - железе составляет $0,05 \%$, т. е. в 3 раза меньше, чем в $\delta$-железе. Чем выше в кристаллизующем металле концентрация углерода, тем выше доля $\gamma$ - железа. Это обстоятельство способствует дальнейшему накоплению серы в расплаве на междендритных границах.

Повышение в металле шва содержания марганца способствует уменьшению дендритной ликвации серы, причем тем существеннее, чем больше в шве концентрация углерода. Положительное влияние марганца объясняется тем, что он, во-первых, являясь элементом аустенитизатором, способствует смещению перитектического превращения на равновесной диаграмме состояния $F e-C$ в направлении более высоких концентраций углерода; во-вторых, вызывая измельчение структуры, способствует рассредоточению серы; в-третьих, уменьшает активность серы и повышает ее растворимость в твердом растворе; в-четвертых, имеет высокое сродство к сере, благодаря чему происходит связывание серы в неметаллических сульфидных включениях, сопровождающееся одновременным уменьшением ее концентрации в жидком металле.

Повышение в металле шва концентрации кремния усиливает дендритную ликвацию серы, причем это проявляется значительнее при более высокой концентрации углерода в металле шва. Указанное влияние кремния можно объяснить следующими причинами. Кремний способствует смещению перитектического превращения на равновесной диаграмме состояния $\mathrm{Fe}-\mathrm{C}$ в область меньших концентраций углерода. Благодаря этому в процессе первичной кристаллизации растет доля $\alpha$-железа. Одновременно кремний повышает активность серы, уменьшая ее растворимость в твердом растворе. Поскольку сродство кремния к кислороду выше, чем у железа и марганца, то он образует оксиды, которые в меньшей степени способны связать серу, чем окислы железа и марганца. Этому способствует также то обстоятельство, что кремний обладает меньшим сродством к сере, чем марганец и железо. В совокупности указанные факторы вызывают накопление серы в расплаве и приводят к повышению уровня дендритной ликвации.

Необходимо отметить, что обогащение серой расплава между дендритами, вызванное ее ликвацией, приводит к образованию сульфидных включений. Результаты исследований свидетельствуют о том, что увеличение дендритной ликвации серы способствует возрастанию количества сульфидных включений на границах между дендритами.

Анализ полученных результатов позволяет сделать вывод, что для обеспечения минимального уровня дендритной ликвации серы в металле шва следует увеличивать в нем концентрацию марганца, уменьшать содержание углерода (менее 0,16-0,17\%), кремния (до 0,10 - 0,20\%) и серы. Учитывая результаты работ $[5,6]$ и данные собственных исследований, приходим к выводу, что концентрация марганца в шве должна быть ограничена 1,2-1,5\%.

Рассмотрим возможные пути осуществления указанных рекомендаций. Как известно, при сварке электродами с покрытием основного вида раскисление-легирование металла шва осуществляется главным образом марганцем. В связи с этим, повышение его концентрации в шве достигается пропорциональным увеличением количества ферромарганца в электродном покрытии. Согласно данным [5, 6], повышение основности шлака или электродного покрытия способствует увеличению в шве концентрации марганца и одновременно снижает концентрацию кремния. Повышение 
основности шлака (за счет увеличения в его составе содержания $\mathrm{CaO}$ и $\mathrm{MgO}$ ) и увеличение в сварочной ванне концентрации марганца способствует также десульфурации металла шва [3]. Таким образом, повышение однородности микрораспределения серы в металле шва может быть достигнуто путем увеличения основности электродного покрытия (предпочтительно за счет использования карбонатов кальция и магния) и введения в его состав оптимального количества ферромарганца.

\section{Выводы:}

1.Методами электронной микроскопии и микрорентгеноспектрального анализа получены систематические количественные данные о дендритной ликвации серы в сварных швах на низкоуглеродистых и низколегированных сталях.

2.Увеличение в металле шва концентрации углерода и кремния вызывает повышение уровня дендритной ликвации серы, что объясняется развитием перитектического превращения, расширением температурного интервала кристаллизации стали, ростом активности серы и возможным смешением перитектического превращения в сторону меньших концентраций углерода. Особенно резко повышается уровень дендритной ликвации серы при содержании в шве углерода свыше $0,15-0,16 \%$.

3.Легирование металла шва марганцем препятствует дендритной ликвации серы, что объясняется измельчением первичной структуры, снижением активности серы, а также смещением перитектического превращения в область больших концентраций углерода.

4.Для уменьшения дендритной ликвации серы и повышения трещиностойкости металла шва необходимо обеспечить в нем содержание углерода менее 0,16-0,17\%, кремния $0,1-0,2 \%$ и марганца $1,0-1,2 \%$.

$$
\text { *** }
$$

1. Касаткин Б. С., Россошинский А. А. Влияние легирующих элементов на развитие химической неоднородности сварных швов // Автоматическая сварка._ 1956.— № 6.- С. 104-108.

2. Макаренко В. Д., Грачев С. И., Прохоров Н. Н. и др. Сварка и коррозия нефтегазопроводов Западной Сибири / // Под ред.В. Д. Макаренко.- Киев: Наукова думка, 1996. - 549 с.

3. Подгаецкий В. В. Поры, включения и трещины в сварных швах.- Киев: Техника, 1972.-236 с.

4. Позняк Л. А. Исследование влияния марганца на развитие ликвации серы в сварных швах углеродистых сталей // Автоматическая сварка.- 1958.- № 1.- С. 80-86.

5. Походня И. К., Коляда Г. Е.,. Явдощин И. Р и др. Прогнозирование химического состава металла, наплавленного электродами с рутиловым и ильменитовым покрытиями/ // Автоматическая сварка.— 1976.— № 7.- С. 1 -4.

6. Походня И. К., Явдощин И. Р. Кремневосстановительный процесс при сварке электродами с рутиловым покрытием // Автоматическая сварка.— 1971.— № 10.- С. 21-23.

7. Россошинский А. А. Металлография сварных швов.- М.:Машгиз, 1961.— 207 с.

8. Фаст Дж. Д. Взаимодействие металлов с газами. / Т. 2.: Кинетика и механизм реакций.- М.: Металлургия, $1975 .-352$ с.

9. Шоршоров М. Х., Ерохин А. А., Чернышева Т. А. Горячие трещины при сварке жаропрочных сплавов.- М.: Машиностроение, 1973.- 258 с.

\section{Николаенко А.С.}

\section{Обоснование базовой конструкции исполнительного магнитожидкосного сенсора}

Балаковский Инженерно-Технологический Институт - филиал федерального государственного автономного образовательного учреждения высшего образования «Национальный исследовательский ядерный университет «МИФИ»

doi:10.18411/spc-12-02-2018-21

(Россия, Балаково)

idsp: 000001:spc-12-02-2018-21

Постановка задачи. Разработка базовой конструкции МЖС. Принцип действия данного прибора. 